\title{
Analysis of the Problems and Countermeasures Faced by Chemical Industry Parks
}

\author{
HEMaoning WANGKaiyuan \\ Safet Risk Control Technology Research Institute \\ Qingdao China \\ 18766565278@163.com
}

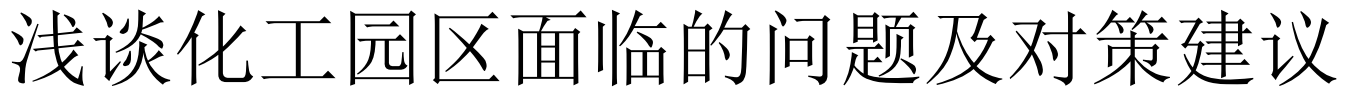

\author{
何茂宁 1 王凯媛 2 \\ 赛飞特风险防控技术研究院 \\ 青岛 266000 中国 \\ 18766565278@163.com
}

\begin{abstract}
With the acceleration of the pace of global economic integration and the recent development of the number, quality and scale of domestic chemical parks, domestic new chemical projects have shown a trend of gathering and development in various chemical parks, but with Jiangsu Xiangshui Chemical Park “The occurrence of the 321" explosion accident, China's chemical park management problem has once again been highlighted. As an important growth point of the economy, the chemical park brings huge economic benefits, but it also brings serious environmental impact and security instability. Under the background of the transformation and upgrading of the entire chemical industry in China and the transformation of new and old kinetic energy, the chemical industry park has played a strong guiding role in the direction of industrial development, capacity adjustment and division of labor, and support for production factors. At the same time, chemical enterprises in the chemical parks have concentrated development, including many. A wide range of hazardous chemicals and major hazards are involved, and hidden dangers such as leakage, fire, explosion and other major safety accidents are lurking. The management of chemical parks is particularly important for the development and even survival of the entire chemical park. This paper analyzes the status quo of safety and emergency in chemical parks, analyzes and summarizes the problems existing in the management of domestic chemical parks, and puts forward countermeasures and suggestions for solving the problems of chemical park management in China, in order to improve the management status of chemical parks in China and promote the science of chemical parks. Development provides help.
\end{abstract}

\section{Keywords—Chemical Industry Park}

摘要一随着全球经济一体化步伐的加快, 以及近期国内化 工园区从数量、质量及规模上的发展, 国内新建化工项目已 呈现出向各种化工园区集聚发展的态势, 但随着江苏响水化 工园区 “ 321 ” 爆炸事故的发生, 我国化工园区管理问题又一
次被突显起来, 作为经济重要的增长点, 化工园区带来巨大的 经济效益, 但同时也带来了严重的环境影响和安全不稳定影 响。在国内整个化工行业转型升级、新旧动能转换大背景 下, 化工园区对产业发展方向、产能整合调整及分工、生产 要素支撑等方面起到强力引导作用, 同时化工园区中化工企 业集中发展, 其中不乏涉及种类众多的危险化学品及重大危 险源, 潜伏着发生泄漏、火灾、爆炸等重大安全事故的隐 患, 化工园区管理对于整个化工园区的发展甚至生存而言就 显得尤为重要。本文分析化工园区的安全与应急现状, 对目 前国内化工园区管理中存在的问题进行了分析总结, 提出了解 决我国化工园区管理问题的对策和建议, 为改善我国化工园 区管理现状、促进化工园区科学发展提供帮助。

关键词一化工园区

\section{I. 引言}

自 “十三五” 以来, 我国化工园区建设掀起了又 一个高潮, 进入了提质增效的新阶段。据统计, 截至 2018 年底, 全国以石油和化工为主导产业的工业园 区共有 676 家, 总产值约占国内石油和化学工业总产 值的 $60 \%$, 其中国家级化工园区（包括经济技术开发 区、高新区） 57 家, 占比为 8.4\%; 省级化工园区 351 家, 占比为 $51.9 \%$; 地市级化工园区 268 家, 占比为 39.6。全国已形成石油和化学工业产值超千亿的超大 型园区 14 家, 占比为 $2.07 \%$; 500 亿-1000 亿的大型 园区 33 家, 占比为 $2.88 \%, 100$ 亿-500 亿的中型园 区 224 家, 占比为 $33.13 \%$; 年产值 100 亿元以下的 园区 405 家, 占比为 59.91 , 反映出我国化工园区数 
量过多，一些园区体量过小，协同效应、规模效应不 明显。

II. 对目前国内化工园区管理现状的分析

近期化工园区事故多发, 特别是江苏响水 “ 3 - 21 ” 化工厂爆炸特别重大事故, 随后发生山东 济南 “ 4.15 ”重大着火中毒事故, 河南的 “ 7 ・ 19” 义马气化厂爆炸事故, 暴露出化工园区安全管理还存 在不足和短板, 特别是园区规划布局、应急救援能 力、化工园区管理等方面依然薄弱, 一些问题还非常 突出, 必须引起高度重视。

（一）化工园区安全监管体制与其高风险性、基 础性产业地位不相适应

一是我国化工园区安全管理涉及工信、质检、环 保、交通等部门, 容易出现相互推诿、有的成为监管 盲区。二是化工园区的安全监管由各级地方政府部门 负责, 地方政府更强调经济发展和就业, 不能正确处 理安全生产与经济发展的关系, 往往为保地方经济发 展和就业, 放松了准入门槛, 导致大量低端项目上 马, 小化工企业安全监管执法宽松软。三是化工园区 的安全监管机构执法权力有限, 人员专业化程度低, 安全监管力量薄弱, 有的市县应急局主管危化品安全 的副局长不懂化工安全, 有的甚至是中文专业背景, 有的市县应急局危化处 (科) 安监人员没有一个是学 化工的, 抓危化品安全监管显得力不从心。

（二）化工园区发展参差不齐, 发展质量堪忧

除了少数国有大型化工企业、中外合作化工企业 拥有先进的生产设备和先进的管理制度, 大量的小化 工企业技术设备落后、管理水平差。同时, 有相当数 量化工园区仅仅是将小化工企业简单的集中在一起, 没有形成上下游产品关系, 化工园区的集群优势没有 发挥出来, 反而使单一分散的安全风险集中形成了较 大规模的安全风险, 极易造成事故的连锁反应和严重 后果。另外, 很多园区安全管理水平低下, 基础配套 设施不齐全, 应急救援能力薄弱, 安全与环境风险隐 患严重。
（三）化工行业（园区）缺乏科学合理的规划 许多市县由于化工园区总体布局缺乏合理规划, 造成化工园区、化工企业与城市聚居区、重要设施、 敏感目标之间的安全防护距离不足, 以及部分油气管 道被城市建筑物占压、安全距离不足、交叉穿越等问 题。同时, 各地方对已建设的化工园区底数不清, 对 于产业类型、规模、工艺技术水平、重大危险源问题 等掌握不清, 形成了潜在的安全风险。随着东部发达 地区化工产业结构的调整, 一些在东部地区被淘汰的 化工企业有可能向西部地区转移, 如江苏等地区被淘 汰或退出企业组团到内蒙古等西部省区投资, 当地政 府认为是发展机会, 结果是这些已淘汰的落后化工工 艺技术转移内蒙古等西部省区, 使得化工安全风险扩 大到西部省区。

\section{III. 化解化工园区系统性风险的对策措施}

近年来化工事故多发是化工行业（园区）系统性 风险的显现, 着眼于化解化工行业 (园区) 系统性风 险, 提出以下对策建议。

（一）规范化工园区发展秩序

一是加大化工产业结构调整力度。国家层面出台 化工产业结构调整政策, 提高设立化工园区及企业入 园的准入门槛, 从严审批化工项目和化工园区, 淘汰 化工行业落后产能, 逐步退出安全条件差的小型化工 企业。借鉴煤矿行业兼并重组的经验, 推动化工行业 兼并重组。二是优化化工行业布局。制定全国化工行 业总体规划, 对全国化工产业合理布局, 各地要合理 规划专门区域用于发展化工行业, 稳步推进化工企业 进园入区, 逐步化解化工行业发展和城镇化发展之间 的矛盾, 同时也防止低水平、低安全门槛的化工企业 向中西部转移。三是治理整顿现有化工园区。对现有 化工园区进行重新认定, 不符合安全环保条件的低水 平化工园区（化工集中区）一律关闭, 对保留下来的 化工园区着力提高一体化管理水平。四是加强化工行 业源头治理。在制定化工园区规划总体规划时, 要将 安全因素置于首要位置, 科学合理规划化工园区, 园 
区安全生产和应急救援基础设施要与园区生产设施同 步规划、同步建设、同步验收。

\section{（二）改革化工园区安全监管体制}

加强化工园区管理, 在国家层面和地方层面均要 明确化工园区管理部门，从化工园区规划、企业准 入、规划布局、建设、运行、退出等全过程进一步加 强化工园区管理。三是完善化工安全监管责任体系, 对化工安全监管涉及的众多部门的安全生产责任进一 步完善。

\section{（三）加强化工园区法规标准建设}

制定颁布《危险化学品安全法》以及配套的行政 法规和部门规章, 对过时的标准规范进行修订。制定 针对化工园区的标准，对化工园区的企业准入、规划 部局、建设施工、园区安全和应急基础设施建设、园 区安全和应急管理等进行全面系统的规范。形成以 《危险化学品安全法》为龙头, 以若干行政法规和部 门规章为配套, 以大量技术标准为支撑的化工安全法 律体系。

（四）提升化工园区技术装备水平

大力推动中小型化工实行自动化改造, 企业要充 分利用互联网、物联网、高科技时代信息化手段，把 企业安全监管工作与生产经营深度有机融合, 推动提 高企业安全信息化、精准化、智能化、动态化、高效 化水平。要深入借鉴采纳先进方法技术, 大力推广化
工过程安全管理、自动化控制、安全仪表系统、高风 险特殊作业移动监测监控系统、危险与可操作性分 析、定量风险评估、油气管道高后果区管理等先进方 法技术, 完善安全管理理念模式, 大幅降低高危岗位 现场作业人员数量, 提高本质安全水平和安全保障能 力。

\section{IV. 结语}

通过分析我国化工园区的安全与应急现状, 对目 前国内化工园区建设及管理中存在的安全监管体制、 化工园区发展质量、化工园区总体布局及发展规划等 方面存在的不足进行了分析讨论。从防范化工园区系 统性风险的角度、化解化工园区系统性风险方面, 进 一步提出了规范化工园区发展秩序、改革化工园区安 全监管体制、加强化工园区法规标准建设及提升化工 园区技术装备水平等措施建议, 能够助力改善我国化 工园区管理现状、促进化工园区科学发展、提升化工 园区服务经济社会发展能力。

\section{参考文献}

[1] 蒋苏毓. 浅谈化工园区的安全管理[J]. 河南化工, 2014(10):27-29.

[2] 谢勇. 基于风险理论的化工园区安全监管体系研究[D]. 中国地质 大学 (北京), 2010.

[3] 韩志勇. "浅谈化工园区安全生产 “四位一体” 监管体系."[J] 中 国化工贸易.7(2013):167-167. 